\title{
Bacterial Ethylene Synthesis from 2-Oxo-4-thiobutyric Acid and from Methionine
}

\author{
By SHAHLA MANSOURI AND ALAN W. BUNCH* \\ Biological Laboratory, University of Kent, Canterbury, Kent CT2 7NJ, UK
}

(Received 3 August 1989; accepted 15 August 1989)

\begin{abstract}
The ability of selected bacterial cultures to synthesize ethylene during growth in nutrient broth supplemented with methionine or 2-oxo-4-methylthiobutyric acid (KMBA) was examined. Although most cultures transformed KMBA into ethylene, only those of Escherichia coli SPAO and Chromobacterium violaceum were able to convert exogenously added methionine to ethylene. In chemically defined media, $E$. coli SPAO produced the highest amounts of ethylene from methionine and KMBA. This capability was affected by the nature of the carbon source and the type and amount of nitrogen source used for growth. When glutamate was used as sole source of carbon and nitrogen for growth, the activity of the ethylenogenic enzymes was reduced to $25 \%$ of that observed with cultures grown with glucose and $\mathrm{NH}_{4} \mathrm{Cl}$. Neither methionine nor KMBA significantly affected the ethylenogenic capacity of $E$. coli SPAO. Menadione and paraquat, compounds that generate superoxide radicals, stimulated ethylene synthesis by harvested cells, but not by cell-free extracts of E. coli SPAO. In addition, cells of Pseudomonas aeruginosa, which produced no ethylene in culture in the presence of exogenously added KMBA, yet possessed the necessary enzymes in an active form, were able to synthesize ethylene from KMBA when incubated with menadione or paraquat.
\end{abstract}

\section{INTRODUCTION}

Many plants and micro-organisms are capable of synthesizing ethylene (Primrose \& Dilworth, 1976; Yang, 1980; Adams \& Yang, 1981). Methionine is the precursor of ethylene in all higher plants, some species of fungi and the majority of bacteria examined (Primrose, 1979). In plants, ethylene affects growth and development (Yang, 1985). Microbially produced ethylene, especially in waterlogged soils, has deleterious effects on plants (Primrose \& Dilworth, 1976). However, the main metabolic route for the transformation of methionine into ethylene differs in plants and bacteria. In plants 1-aminocyclopropane-1-carboxylic acid is an intermediate (Adams \& Yang, 1979). Bacterial ethylene synthesis is via 2-oxo-4-methylthiobutyric acid (KMBA) (Primrose 1977; Ince \& Knowles, 1985). Both processes require oxygen, although oxygen-derived radicals may actually be the substrates.

The enzymes involved in the synthesis of ethylene in bacteria have not been characterized. In Escherichia coli SPAO, the first step in the process leading to the production of KMBA is thought to involve a transaminase (Primrose 1977; Ince \& Knowles 1985). Conversion of KMBA to ethylene by the soluble fraction of cell-free systems requires, in addition to oxygen, $\mathrm{Fe}^{3+}$, EDTA and NAD $(\mathrm{P}) \mathrm{H}$. Ethylene synthesis by whole cells has similar requirements. Other products of the reaction are carbon dioxide and methanethiol (Ince \& Knowles, 1986).

There has been much speculation on the function that ethylene synthesis fulfills in microorganisms. In common with other secondary metabolic processes its significance in the metabolism of the producer cell is still poorly understood. Ince \& Knowles (1985) suggested that the main function of the system may be to recover the amino nitrogen from methionine, but

Abbreviation: KMBA, 2-oxo-4-methylthiobutyric acid. 
other roles are possible. The most intriguing of these is the possibility that production of KMBA from methionine allows the cell to quench excess oxygen radicals synthesized under aerobic conditions. No ethylene is produced when E. coli is grown anaerobically (Primrose, 1977).

The observation that a wide variety of bacteria are capable of synthesizing ethylene will, if the mechanisms involved are similar, allow a comparison to be made of the way the process is related to the rest of metabolism in these micro-organisms. In this paper we examine the ethylenogenic capabilities of a number of selected bacteria grown in media supplemented with methionine and KMBA. In addition, we determine the effect of a variety of metabolites involved in ethylene synthesis, nitrogen metabolism and oxygen radical generation on ethylenogenesis by bacteria selected from the first stage of the investigation.

\section{METHODS}

Organisms and growth conditions. Escherichia coli SPAO was obtained from Dr C. S. Dow (University of Warwick, UK). The other bacteria used were acquired from the culture collections indicated in Table 1. All bacteria were maintained on nutrient agar slopes $(2.8 \%, \mathrm{w} / \mathrm{v}$; Oxoid) in the dark at room temperature. Subculturing onto fresh slopes was done at monthly intervals. Fresh cultures were prepared from lyophilized vials of bacteria stored under vacuum at $4{ }^{\circ} \mathrm{C}$.

Nutrient broth cultures $(2.5 \%, \mathrm{w} / \mathrm{v}$; Oxoid) plus additions as stated were grown in $250 \mathrm{ml}$ conical flasks sealed with serum caps. The caps, used to prevent loss of ethylene, were sterilized in alcohol before use. Each flask contained $50 \mathrm{ml}$ of medium and was inoculated with a $2 \%(\mathrm{v} / \mathrm{v})$ inoculum from a starter culture grown for $24 \mathrm{~h}$. Starter cultures were inoculated by washing the contents of an agar slant into a $250 \mathrm{ml}$ conical flask sealed with a cottonwool plug. Each flask contained $100 \mathrm{ml}$ of medium.

In other experiments, the chemically defined medium described by Ince \& Knowles (1985) was used. It consists of basal salts medium to which $10 \mathrm{mM}$-glucose plus $3 \mathrm{mM}-\mathrm{NH}_{4} \mathrm{Cl}$ are added as the carbon and nitrogen source respectively. Other additions or variations are described elsewhere in this paper. Amino acids and oxo acid stock solutions were filter-sterilized using a $0.45 \mu \mathrm{m}$ cellulose nitrate filter (Whatman). All other components were sterilized by autoclaving at 15 p.s.i. for $15 \mathrm{~min}$. The volume of media used in each $250 \mathrm{ml}$ conical flask, sealed as described above, was $30 \mathrm{ml}$.

All cultures were incubated at $35^{\circ} \mathrm{C}$ in an orbital shaker (RS-T Incubator Rotary Shaker) 200 r.p.m. in the dark.

Harvesting cells and preparation of cell-free extracts. Cells were havested from cultures and their ethylenogenic activities determined by the methods described by Ince and Knowles (1985). (However, the cells were grown without added methionine or KMBA, and $250 \mathrm{ml}$ of culture in 2 litre conical flasks sealed with Suba-seals were used.) To prepare cell-free extracts a cell suspension $(5-7 \mathrm{ml})$ containing $40-45 \mathrm{mg}$ dry wt bacteria $\mathrm{ml}^{-1}$ was disrupted by sonication using an MSE sonicator (model $150 \mathrm{~W}$ ) with the amplitude set to one and the power to high. Cells were sonicated for $4 \times 20 \mathrm{~s}$ periods with $20 \mathrm{~s}$ intervals for cooling between each period. Intact bacteria were removed by centrifugation $\left(15000 \mathrm{~g}, 10 \mathrm{~min}, 4^{\circ} \mathrm{C}\right)$ and the crude extract kept at $4{ }^{\circ} \mathrm{C}$ and assayed for ethylene production within $2 \mathrm{~h}$ of preparation.

Assay procedures. Growth and bacterial biomass were determined by the methods described by Ince \& Knowles (1985). Ethylene produced when using the same assay systems as described by these workers was determined as follows. Samples of the gas-phase $(0.5-1 \mathrm{ml})$ were removed from the head space of the assay vessels using a $1 \mathrm{ml}$ gas-tight syringe (SGE; Ringwood, Australia). The gas samples were injected into a gas chromatograph (PyeUnicam series 204), equipped with a flame ionization detector and linked to a model CDPI computing integrator. A $1.6 \mathrm{~m} \times 6 \mathrm{~mm}$ glass column packed with Porapak $\mathrm{R}$ (Waters) was used at $85^{\circ} \mathrm{C}$, with the injector at $105^{\circ} \mathrm{C}$ and detector at $175^{\circ} \mathrm{C}$. Using nitrogen as the carrier gas at $40 \mathrm{ml} \mathrm{min}^{-1}$ ethylene had a retention time of $80 \mathrm{~s}$. Quantitative measurements were obtained by comparison with a standard curve calibrated by injecting known amounts of ethylene into the gas chromatograph. No correction was made for dissolved ethylene in the liquid phase since this was always less than $1 \%$ of the total present.

Glucose concentrations in culture media or incubation mixtures were determined using a test-combination (GOD-Perid; Boehringer); ammonia was quantified by the procedure described by Fawcett \& Scott (1960). Samples $(1 \mathrm{ml})$ of the cultures were removed and centrifuged in a microcentrifuge (Micro-Centaur; MSE) at full speed for $5 \mathrm{~min}$. The resultant supernatants were used for the assays.

KMBA concentrations in incubation mixtures were determined following derivatization with 2,4dinitrophenylhydrazine, and extraction and separation of the hydrazone by HPLC as described by Hemming \& Gubler (1979).

Oxygen uptake by bacteria was measured with a Clark polarographic electrode (Rank Bros) connected to a chart recorder. Assays were done at $37^{\circ} \mathrm{C}$ with a final volume of $3 \mathrm{ml}$ in the electrode chamber. The reaction mixtures contained about $0.32 \mathrm{mg}$ cell dry $\mathrm{wt} \mathrm{ml}^{-1}$. Glucose and KMBA were added to give a final concentration of $10 \mathrm{mM}$; when used the final menadione concentration was $5 \mathrm{mM}$. 
Materials. Analytical grade chemicals were used throughout the study where possible. All chemicals were obtained from Fisons, except tetrabutylammonium hydroxide which was purchased from Aldrich and the ubiquinones which were from Hoffmann-La Roche. All biochemicals and enzymes were obtained from Sigma and were used without further purification. Glass-distilled water was used throughout for preparations of buffers and culture media.

\section{RESULTS AND DISCUSSION}

\section{Ability of selected bacteria to synthesize ethylene from methionine}

Cultures grown in nutrient broth. Previous studies on microbial ethylene production have shown that many bacteria can synthesize ethylene from methionine (Primrose 1977; Billington et al., 1979). Ince \& Knowles (1985) showed in E. coli that KMBA was an intermediate on this pathway, most likely resulting from the transamination of methionine. These workers also identified media components such as $\mathrm{Fe}^{3+}$ and EDTA, which can greatly stimulate ethylene synthesis from methionine and KMBA. Table 1 compares the ability of a variety of bacteria to synthesize ethylene during growth on nutrient broth supplemented with $\mathrm{Fe}^{3+}$ and EDTA, a medium that allows extensive ethylene production by $E$. coli SPAO. This bacterium was selected due to its high ethylenogenic capacity on a chemically defined medium and the extensive studies by others on ethylene production by this organism (Primrose, 1976, 1977; Ince \& Knowles, 1985). The other bacteria were selected to allow comparison between taxonomically similar and diverse types and also on their known ability to produce similar metabolites from methionine to those observed during ethylene synthesis (e.g. methanethiol).

Apart from E. coli SPAO only Chromobacterium violaceum synthesized detectable amounts of ethylene from methionine. The detection limits for the analytical process used were between $0.03-0.05 \mu \mathrm{mol}$ ethylene per flask per day. No ethylene was detected in cultures which were not supplemented with methionine or KMBA. Although nutrient broth contains methionine, most of this is probably used for growth-related metabolic functions, leaving little available for ethylene synthesis which began in cultures supplemented with methionine after most of the growth had taken place.

The majority of the bacteria selected were able to metabolize KMBA to ethylene (Table 1). $E$. coli $\mathrm{K} 12$ synthesized much less ethylene than $E$. coli SPAO even though it apparently grew

\section{Table 1. Ethylene production by different bacterial species grown on mutrient broth}

Ethylene production and $\mathrm{OD}_{540}$ were measured after $24 \mathrm{~h}$ growth on nutrient broth containing $\mathrm{Fe}^{3+}$ $(0.244 \mathrm{mM})$ and EDTA $(0.4 \mathrm{mM})$, and supplemented with KMBA or methionine $(2.7 \mathrm{mM})$. (This concentration of methionine is optimal for ethylenogenesis by $E$. coli SPAO.) Results are means of four experiments; the variance in all cases was less than $10 \%$. ND, not determined.

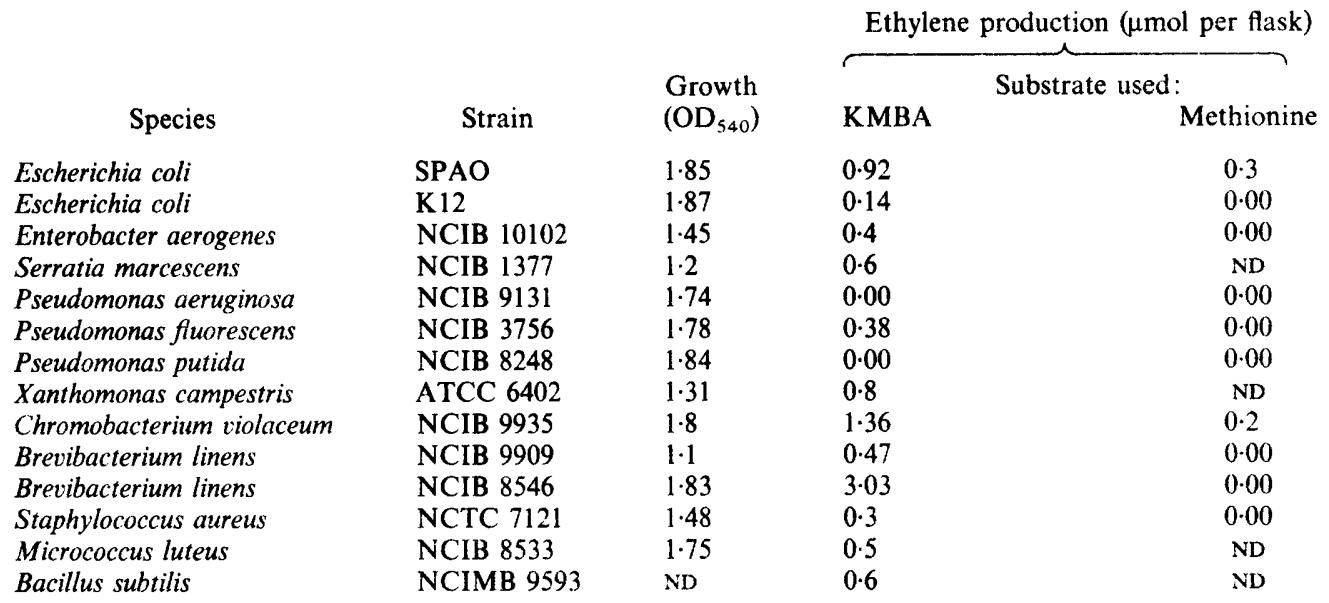



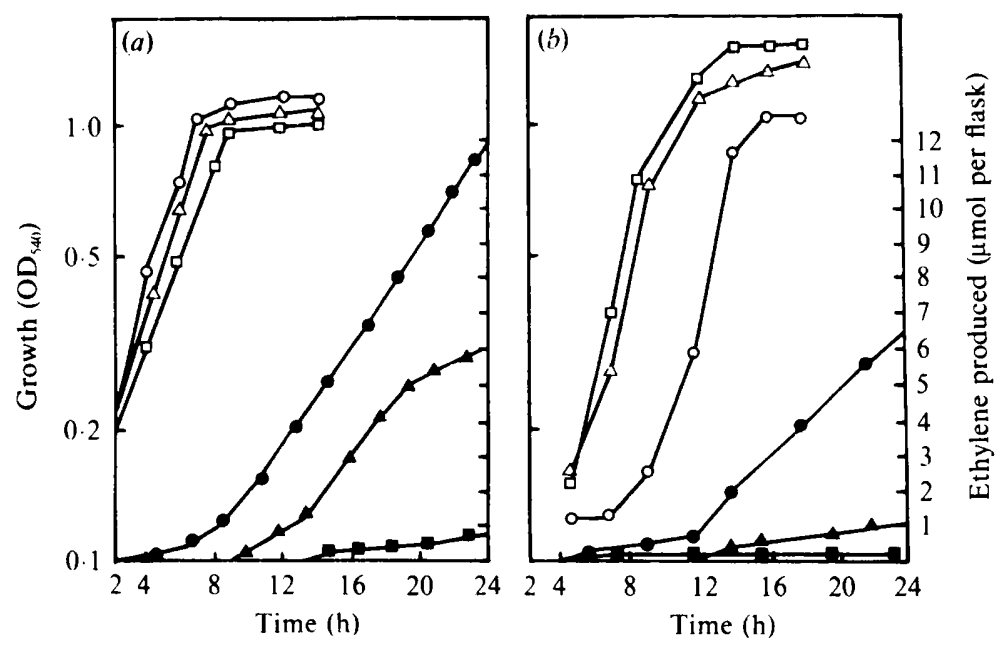

Fig. 1. Growth (open symbols) and ethylene production (closed symbols) by (a) E. coli SPAO and (b) $C$. violaceum in defined medium ( $30 \mathrm{ml}$ ) containing $10 \mathrm{~mm}$-glucose and $3 \mathrm{mM}-\mathrm{NH}_{4} \mathrm{Cl}$. Results are means of three experiments with a variance for each data point of less than $10 \%$. $\square, \square$, Unsupplemented medium; $O, O$, medium supplemented with $2.7 \mathrm{mm-KMBA}: \triangle, \boldsymbol{\Delta}$, medium supplemented with $2 \cdot 7$ mM-methionine.

equally well under the conditions used. Pseudomonas fluorescens was the only pseudomonad capable of synthesizing ethylene from KMBA.

There are many possible biochemical reasons for these differences between strains and species. For example, the ability to transport amino and oxo acids into the cell may differ considerably, which could explain why pseudomonads appear to be unable to convert exogenously supplied methionine to KMBA. (Pseudomonads have been reported as being able to transaminate methionine to KMBA under a wide range of growth conditions.) In our experiments neither $P$. aeruginosa nor $P$. putida utilized either methionine or KMBA for the synthesis of ethylene and none of the ethylenogenic bacteria synthesized ethylene in unsupplemented media. These results raise important questions as to the nature of the initial substrate for ethylene in soil and suggest that relatively few bacteria may be involved.

Cultures grown in defined media. It was not possible to compare ethylene production by bacteria growing on the same defined medium. Both strains of Brevibacterium linens tested were unable to grow on the defined medium used for E. coli SPAO. Xanthomonas campestris and Enterobacter aerogenes grew well on this medium but only produced small amounts of ethylene $(0.16$ and $0.18 \mu \mathrm{mol}$ ethylene per flask per day respectively) when grown in the presence of KMBA and no ethylene when methionine replaced KMBA. Similar results were obtained for $P$. fluorescens. Fig. 1 compares ethylene production by $E$. coli SPAO and $C$. violaceum during batch culture in defined medium in the presence or absence of either methionine or KMBA. E. coli SPAO produced $12 \mu \mathrm{mol}$ ethylene after $24 \mathrm{~h}$ growth in medium supplemented with KMBA. Ethylene production continued for another $24 \mathrm{~h}$ and reached a maximum of $20 \mu \mathrm{mol}$ per flask. Only $0.6 \mu$ mol ethylene per flask was synthesized in the absence of any supplements. Growth of $E$. coli SPAO was similar in all cases. $C$. violaceum is able to synthesize hydrogen cyanide from the amino acid glycine, a process stimulated by methionine (Knowles \& Bunch, 1986). It apparently grew better in the defined medium than $E$. coli SPAO except when KMBA was present. However, ethylenogenesis was low in the absence of KMBA. The presence of methionine only slightly enhanced ethylenogenesis. Although $P$. aeruginosa grew to the same extent in defined medium with or without KMBA or methionine no ethylene was detected.

Conversion of KMBA to ethylene by cultures of E. coli SPAO (Fig. 1a) showed no signs of stopping after $24 \mathrm{~h}$. Therefore substrates such as $\mathrm{NADH}$ and $\mathrm{O}_{2}$, which are required by cell-free extracts for the conversion of KMBA to ethylene (Ince \& Knowles, 1986), are presumably not 

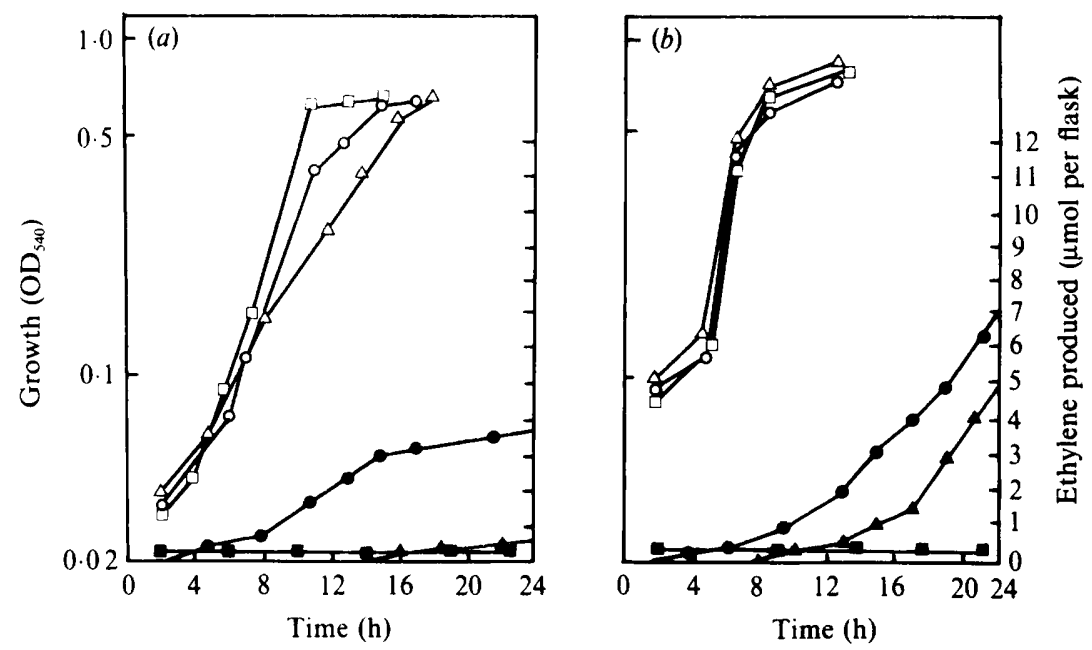

Fig. 2. Growth (open symbols) and ethylene production (closed symbols) by E. coli SPAO grown in a defined medium $(30 \mathrm{ml})$ containing $(a)$ glutamate $(6 \mathrm{mM})$ as sole carbon and nitrogen source and $(b)$ glutamate $(3 \mathrm{mM})$ as sole carbon source and $\mathrm{NH}_{4} \mathrm{Cl}(3 \mathrm{mM})$ as additional nitrogen source. Results are means of five experiments with a variance for each data point of less than $8 \%$. $\square, \square$, Unsupplemented media; $\bigcirc, O$, media supplemented with $2.7 \mathrm{mM}-\mathrm{KMBA} ; \triangle, \Delta$, media supplemented with $2.7 \mathrm{mM}$ methionine.

limiting the process at this stage. In contrast, cultures growing in media supplemented with methionine had lower rates of ethylene synthesis after $20 \mathrm{~h}$ incubation. This could reflect the use of methionine for other biochemical processes or limitation of co-substrates such as 2oxoglutarate, and illustrates the likely importance of the metabolic status of the cell in determining the amount of ethylene synthesized. Although the enzyme required to convert methionine to KMBA is present throughout growth in E. coli SPAO (Ince \& Knowles, 1985), no ethylene is produced until the stationary phase. This suggests the presence of competing pathways for methionine metabolism.

To try to answer some of the problems raised by the above work, the physiology of ethylenogenesis by $E$. coli SPAO was investigated in further detail.

Effect of the composition of the growth medium on ethylene synthesis by cultures of E. coli

Nitrogen source. The biochemical function of ethylenogenesis is unknown. Ince \& Knowles (1985) suggested that its primary role could be to allow the recovery of the amino nitrogen of methionine under nitrogen-limited conditions of growth. Methionine cannot be used as a sole source of carbon and nitrogen or of carbon for growth. When used as the sole source of nitrogen (with $10 \mathrm{~mm}$-glucose as the carbon source) no additional growth was observed compared to cultures grown with an amount of $\mathrm{NH}_{4} \mathrm{Cl}$ equivalent to the methionine. Growth was also very slow (doubling time about $7 \mathrm{~h}$ ). Ethylene synthesis did not occur until the end of the growth phase and was much lower $(0.5 \mu \mathrm{mol}$ per fiask) than in medium with $10 \mathrm{~mm}$-glucose and $3 \mathrm{~mm}-$ $\mathrm{NH}_{4} \mathrm{Cl}$. Increasing the methionine concentration from 2.7 to $10 \mathrm{mM}$ did not affect growth or the amount of ethylene synthesized (results not shown).

When glutamate was the sole source of carbon and nitrogen for growth, ethylene production was greatest when KMBA was present (Fig. $2 a$ ), although the rate of synthesis was slow after $14 \mathrm{~h}$ incubation. Little ethylene was synthesized by cells grown in unsupplemented media or media to which methionine had been added.

When glutamate was the sole source of nitrogen but with glucose as additional carbon source ethylene synthesis was extensive in media supplemented with KMBA or methionine. In both cases ethylenogenesis was still continuing after $24 \mathrm{~h}$ incubation. The amounts of ethylene synthesized by this time were 7 and $4.6 \mu \mathrm{mol}$ per flask respectively. 


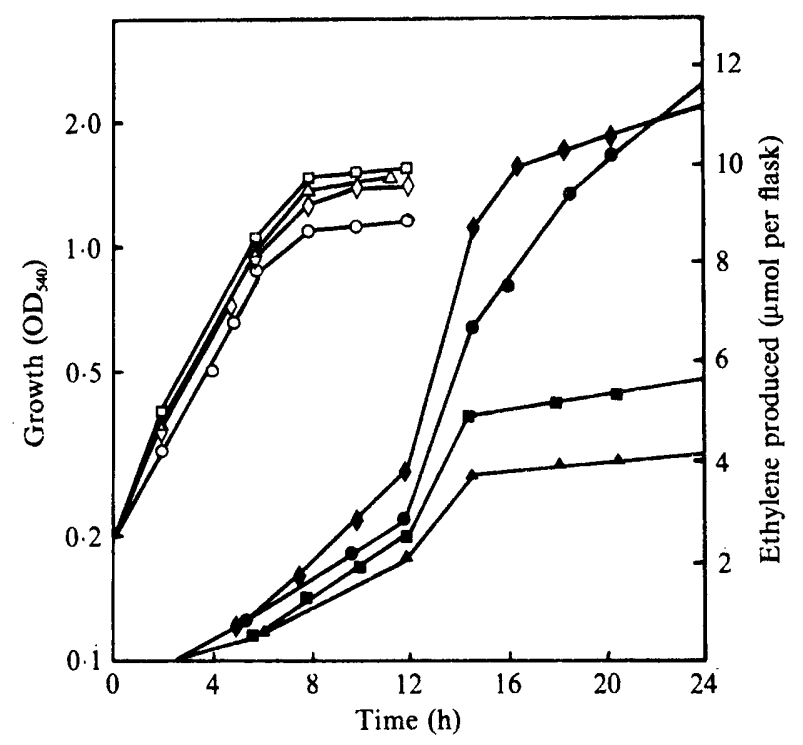

Fig. 3. Growth (open symbols) and ethylene production (closed symbols) by $E$. coli SPAO grown in medium ( $30 \mathrm{ml}$ ) containing $10 \mathrm{mM}$-glucose, $2.7 \mathrm{mM}-\mathrm{KMBA}$ and different starting concentrations of $\mathrm{NH}_{4} \mathrm{Cl}$. Results are means of five experiments with a variance for each data point of less than $10 \%$. $0,0,3 \mathrm{mM}-\mathrm{NH}_{4} \mathrm{Cl} ; \diamond, \diamond, 5 \mathrm{mM}-\mathrm{NH}_{4} \mathrm{Cl} ; \square, \square, 10 \mathrm{mM}-\mathrm{NH}_{4} \mathrm{Cl} ; \triangle, \Delta, 15 \mathrm{mM}-\mathrm{NH}_{4} \mathrm{Cl}$.

Methionine can be used by $E$. coli as a nitrogen source for growth. As the carbon cannot be utilized this indicates that the ethylenogenic pathway is probably the main route for methionine catabolism in this bacterium. However, it cannot be the only route because, with methionine as sole nitrogen source, ethylene is not produced until after most of the growth has taken place. As further metabolism of ethylene or methionine- $\gamma$-lyase during or after growth has not been detected (N. J. Shipston \& A. W. Bunch, unpublished), the nature of the pathway remains to be resolved.

With glutamate as sole source of carbon and nitrogen in medium supplemented with methionine, little ethylene was produced. The presence of methionine also slowed down growth. Under these conditions it is likely that other pathways compete for available glutamate so that very little 2-oxoglutarate is available for the ethylenogenic system. As ethylenogenesis from $\mathrm{KMBA}$ is also discontinuous, cosubstrates for the latter stages of ethylene synthesis may also be limiting. When glutamate was used as sole nitrogen source but with glucose as an additional carbon source for growth, synthesis of ethylene from both KMBA- and methioninesupplemented media was similar. KMBA is excreted into the medium during growth of $E$. coli in the presence of methionine; it is then converted into ethylene (Billington et al., 1979). This could explain the later onset of ethylenogenesis seen in Fig. 2(b).

Effect of $\mathrm{NH}_{4} \mathrm{Cl}$ concentration. The initial concentration of $\mathrm{NH}_{4} \mathrm{Cl}$ in the growth medium affected the amount of ethylene synthesized from KMBA (Fig. 3). Although the growth yield was lower in media containing $3 \mathrm{mM}$ (or less) $\mathrm{NH}_{4} \mathrm{Cl}$, ethylenogenesis was greater. At $\mathrm{NH}_{4} \mathrm{Cl}$ concentrations greater than $5 \mathrm{~mm}$ ethylene production ceased after $16 \mathrm{~h}$ growth. Under these conditions ammonia remained in the culture medium at the end of growth $(3.5 \mathrm{~mm}$ and $7.5 \mathrm{mM}$ when the starting concentration was $10 \mathrm{mM}$ and $15 \mathrm{mM}$, respectively). The rate of glucose consumption was similar when the initial concentration of $\mathrm{NH}_{4} \mathrm{Cl}$ was 5,10 or $15 \mathrm{~mm}$. When $3 \mathrm{mM}-\mathrm{NH}_{4} \mathrm{Cl}$ was used removal of glucose from the medium was slower and after $12 \mathrm{~h}$ growth $1 \mathrm{~mm}$-glucose remained. This was removed during the next $3 \mathrm{~h}$ incubation.

Experiments on washed cells. Cells harvested from batch cultures of E. coli grown for $14 \mathrm{~h}$ with glucose $(10 \mathrm{~mm})$ and $\mathrm{NH}_{4} \mathrm{Cl}(3 \mathrm{mM})$ synthesized ethylene when resuspended in growth medium containing KMBA and glucose but without $\mathrm{NH}_{4} \mathrm{Cl}$. The rate of ethylene synthesis was constant 


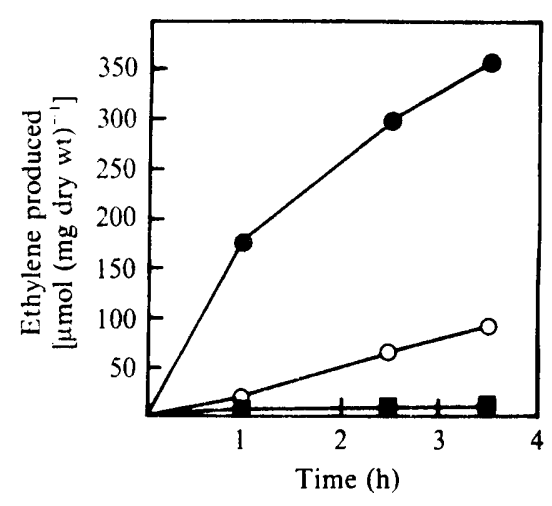

Fig. 4. Enhancement by menadione of ethylene production by washed cell suspensions of $E$. coli SPAO. Bacteria were harvested after $14 \mathrm{~h}$ growth, and washed and resuspended to about $34 \mathrm{mg}$ cell dry wt ml ${ }^{-1}$ in $20 \mathrm{~mm}$-potassium phosphate buffer, $\mathrm{pH} 7 \cdot 2$. Ethylene production was assayed by incubating $0.5 \mathrm{ml}$ washed cell suspensions in basal growth medium containing $10 \mathrm{mM}-\mathrm{KMBA}$ and $10 \mathrm{mM}-\mathrm{glucose}$ but without $\mathrm{NH}_{4} \mathrm{Cl}(\mathrm{O})$, and in the same incubation mixture supplemented with 5 mM-menadione (O). $\square$, Control containing menadione but no bacteria. Results are means of three experiments with a variance for each data point of less than $10 \%$.

from 3 to $22 \mathrm{~h}$ incubation at $21 \cdot 5 \pm 1 \mathrm{nmol}$ ethylene $\mathrm{h}^{-1}$ (mg dry wt) $)^{-1}$. When KMBA was replaced by methionine the rate of ethylene production was $8 \mathrm{nmol} \mathrm{h}^{-1}\left(\mathrm{mg}\right.$ dry wt) ${ }^{-1}$. The presence of either methionine or KMBA in the initial growth medium did not affect the ethylenogenic capacity of such cells. Ethylene production by washed cells was slightly higher (not more than $2 \%$ at $15 \mathrm{~mm}-\mathrm{NH}_{4} \mathrm{Cl}$ ) the greater the $\mathrm{NH}_{4} \mathrm{Cl}$ concentration in the initial growth medium, a result which contrasts with rates of ethylene production by the cultures themselves (see above). Growth on glutamate as sole source of carbon and nitrogen strongly affected the ethylenogenic capacity, lowering it to $25 \%$ of that observed for cells grown on $10 \mathrm{~mm}$-glucose plus $3 \mathrm{mM}-\mathrm{NH}_{4} \mathrm{Cl}$. The ethylenogenic capacity of cells grown on glutamate as sole source of nitrogen was $35 \%$ of that observed for cells grown on $10 \mathrm{~mm}$-glucose plus $3 \mathrm{mM}-\mathrm{NH}_{4} \mathrm{Cl}$.

Addition of 2-oxoglutarate to harvested cells caused a 3-fold increase in the rate of ethylene production from KMBA. The presence of L- or D-methionine lowered ethylene production to $16 \%$ of the control. Oxobutyrate, a product of methionine $\gamma$-lyase, increased the rate of ethylene production by $1 \cdot 5$-fold.

Addition of the protein-synthesis inhibitor chloramphenicol to washed cells from a $12 \mathrm{~h}$ culture of $E$. coli SPAO caused a loss of ethylenogenic capacity during the subsequent $7 \mathrm{~h}$ incubation: $3.6 \mathrm{nmol}$ ethylene (mg dry wt) ${ }^{-1}$ compared to $20 \mathrm{nmol}$ ethylene (mg dry wt) ${ }^{-1}$ in the control to which no chloramphenicol was added.

Relationship between ethylenogenesis and nitrogen metabolism. Several of our results indicated the possibility of such a relationship. For example, greater amounts of ethylene were produced under conditions where ammonium is limiting. Also, growth on glutamate as sole source of carbon and nitrogen or as sole nitrogen source lowered the ethylenogenic activity of harvested cells. However, the presence of either KMBA or methionine in the medium did not increase ethylene production by such cells, even though the experiments with chloramphenicol indicate that there must be some synthesis and inactivation of the enzyme system involved during ethylenogenesis.

The rate of ethylene production from KMBA by harvested cells was enhanced by addition of 2-oxoglutarate. This implies either a possible regulatory role for this oxo acid or that the conversion of endogenous methionine to KMBA is limited by its availability. The results in Fig. 2(a) also suggest a role for 2-oxoglutarate or a catabolite of glutamate in the conversion of KMBA to ethylene by cells in these cultures. The stimulation by 2-oxobutyrate of ethylene production from KMBA by harvested cells is difficult to explain as no methionine- $\gamma$-lyase activity in this strain of $E$. coli has been reported. 
Effects of compounds that generate superoxide radicals. There is substantial evidence that free radicals of oxygen are involved in the conversion of KMBA to ethylene (Yang, 1969; Feierman \& Cederbaum, 1985). We examined the effects of a variety of compounds known to generate superoxide radicals under the conditions used in this study. Both menadione and paraquat increased ethylene production by cells harvested from 12 or $14 \mathrm{~h}$ cultures (by 4- and 2-fold respectively). The optimum concentrations were $2 \mathrm{mM}$ for paraquat and $5 \mathrm{~mm}$ for menadione. Ubiquinone 0 and juglone inhibited ethylene formation from KMBA, whereas 6-hydroxydopamine and ubiquinone 8 did not affect synthesis significantly. Fig. 4 shows the effect of menadione on harvested cells. In the presence of KMBA, a maximum rate of ethylene synthesis of $25 \mathrm{nmol}(\mathrm{mg} \text { dry } \mathrm{wt})^{-1} \mathrm{~h}^{-1}$ was observed. Menadione on its own did not stimulate ethylene synthesis, but in the presence of menadione and KMBA, the rate of ethylenogenesis reached a maximum of $115 \mathrm{nmol}$ ethylene $(\mathrm{mg} \text { dry } \mathrm{wt})^{-1} \mathrm{~h}^{-1}$. Menadione did not affect the rate of KMBA uptake by the cells, nor did it stimulate ethylene production in cell-free extracts. Menadione plus KMBA did not affect uptake of oxygen, which is needed for ethylene synthesis by harvested cells. Menadione but not paraquat inhibited ethylene formation from methionine by $64 \%$.

Cultures of $P$. aeruginosa did not synthesize ethylene (see above) but cells harvested from such cultures did synthesize ethylene in the presence of $5 \mathrm{mM}$-menadione or $2 \mathrm{mM}$-paraquat; the rates were 16 and $1.9 \mathrm{nmol}$ ethylene $\mathrm{h}^{-1}$ (mg dry wt) $)^{-1}$, respectively.

The effects of menadione and paraquat on ethylene production by harvested $E$. coli cells may be related to the ability of these compounds to generate oxygen radicals. However, the effects that these compounds have in $P$. aeruginosa is unlikely to be so straightforward. Although cultures of $P$. aeruginosa cannot convert KMBA to ethylene the cells do possess the necessary enzyme(s). This could indicate a possible function of menadione in the generation of radicals that subsequently interact with KMBA. However, menadione has no effect on the cell-free system, and has no effect on the higher uptake of KMBA by washed cells of $E$. coli SPAO.

\section{Conclusions}

The results presented reveal that the way in which the ethylenogenic system interacts with the rest of metabolism is complicated. Also, the production of ethylene by soil bacteria, which is a major horticultural problem, is less straightforward than had been thought.

We wish to thank Professor C. J. Knowles and Nigel Shipston for many useful discussions, and Ms S. Davies and Mrs J. Williams for typing this manuscript.

\section{REFERENCES}

ADAMS, D. O. \& YANG, S. F. (1979). Ethylene biosynthesis: identification of 1 -aminocyclopropane-1-carboxylic acid as an intermediate in the conversion of methionine to ethylene. Proceedings of the National Academy of Sciences of the United States of America 76, 170-174.

ADAMS, D. O. \& YANG, S. F. (1981). Ethylene the gaseous plant hormone: mechanism and regulation of biosynthesis. Trends in Biochemical Sciences 6 , 161-164.

Billington, D. C., Golding, B. T. \& Primrose, S. B. (1979). Biosynthesis of ethylene from methionine. Isolation of the putative intermediate 4-methylthio2 -oxobutanoate from culture fluids of bacteria and fungi. Biochemical Journal 82, 827-836.

FAWCETT, J. K. \& SCOTT, J. E. (1960). A rapid and precise method for the determination of urea. Journal of Clinical Pathology 13, 156-159.

Feierman, D. E. \& Cederbaum, A. I. (1985). Ethylene production from $\alpha$-keto-4-thiomethylbutyric acid by isolated rat liver cells. Suspension medium, and perfusates in the absence and presence of iron.
Journal of Free Radicals in Biology \& Medicine 1, 155162.

Hemming, B. C. \& Gubler, C. J. (1979). High-pressure liquid chromatography of $\alpha$-keto acid 2,4-dinitrophenylhydrazones. Analytical Biochemistry 92, 3140.

INCE, J. E. \& KNowles, C. J. (1985). Ethylene formation by cultures of Escherichia coli. Archives of Microbiology 141, 209-213.

INCE, J. E. \& KNowles, C. J. (1986). Ethylene formation by cell-free extracts of Escherichia coli. Archives of Microbiology 146, 151-158.

KNOWLES, C. J. \& Bunch, A. W. (1986). Microbial cyanide metabolism. Advances in Microbial Physio$\log y$ 27, 73-106.

Primrose, S. B. (1976). Formation of ethylene by Escherichia coli. Journal of General Microbiology 95, 159--165.

Primrose, S. B. (1977). Evaluation of the role of methional, KMBA and peroxidase in ethylene formation by Escherichia coli. Journal of General Microbiology 98, 519-528. 
Primrose, S. B. (1979). Ethylene and agriculture: the role of the microbe. Journal of Applied Bacteriology 46, $1-25$.

Primrose, S. B. \& Dilworth, M. J. (1976). Ethylene production by bacteria. Journal of General Microbiology 93, 177-181.

YANG, S. F. (1969). Further studies on ethylene formation from $\alpha$-keto- $\gamma$-methylthiobutyric acid or $\beta$ - methylthiopropinoaldehyde by peroxidase in the presence of sulphide and oxygen. Journal of Biological Chemistry 244, 4360-4365.

YANG, S. F. (1980). Regulation of ethylene biosynthesis. Horticultural Science 15, 238-243.

YANG, S. F. (1985). Biosynthesis and action of ethylene. Horticultural Science 20, 41-45. 